\title{
Discussion: Horizontal stress increase induced by deep vibratory compaction
}

K. Rainer Massarsch Dr Tech, Eur Ing

Consulting Engineer, Geo Risk \& Vibration Scandinavia AB, Stockholm,

Sweden (corresponding author: rainer.massarsch@georisk.se)

(Orcid:0000-0001-8906-7452)

Carl Wersäll PhD

Researcher, Department of Civil and Architectural Engineering,

Royal Institute of Technology (KTH), Stockholm, Sweden

Bengt H. Fellenius Dr Tech, PEng

Consulting Engineer, Sidney, BC, Canada
Lech Bałachowski DSc, PhD

Faculty of Civil and Environmental Engineering, Gdańsk University of Technology, Gdańsk, Poland (corresponding author:

lech.balachowski@pg.edu.pl) (Orcid:0000-0002-3240-8313)

Norbert Kurek PhD

Central Branch Director, Menard Polska Sp. z o.o., Warszawa, Poland Jakub Konkol PhD

Faculty of Civil and Environmental Engineering, Gdańsk University of Technology, Gdańsk, Poland (Orcid:0000-0002-5559-7700)

\section{Contribution by L. Bałachowski, N. Kurek and J. Konkol}

Evaluation of the horizontal stress increase induced by deep compaction is one of the most difficult topics in geotechnics. The approach of Massarsch et al. (2020) to determine the overconsolidation ratio (OCR) in compacted soil based on sleeve friction and lateral stress index seems to be questionable. In Figures 12 and 24 of their paper, the irregular shape of the OCR with depth and sharp peaks cannot be physically explained. Moreover, the OCR values based on sleeve friction and lateral stress index are inconsistent. For instance, 14 days after dynamic compaction, the OCR values determined with the lateral stress index (Figure 9) are four to seven times higher than those based on sleeve friction (Figure 7). Even greater inconsistency in the OCR values determined using cone penetration test $(\mathrm{CPT})$ with water pressure measurement (CPTU) and the Marchetti dilatometer test (DMT) was shown for vibroflotation (Figures 12 and 14). Very high OCR values, largely exceeding 100 (Figure 14), estimated with the correlation using the DMT are highly unrealistic. The upper bound of the OCR-based $K_{0}$ should correspond to the passive earth pressure coefficient. Additionally, the use of sleeve friction is generally considered less reliable than the cone resistance, so the proposed correlation (Equation 2) should be used with caution. In the contributors' opinion, it would be better to use the OCR correlations based on combined CPTU and DMT tests, as proposed by Baldi et al. (1986), Monaco et al. (2014) or Marchetti (2015). Additionally, Figure 17 seems to be erroneous, as the report of sleeve friction elaborated using the data from Figure 15 is higher than one at larger depths.

To estimate the OCR of compacted sand, the authors used Equation 12 based on calibration chamber tests with the soil mass prepared by pluviation and then mechanically overloaded (Lee et al., 2011). Such a procedure is, however, quite different to the mechanisms of deep soil vibratory compaction with rearrangement of grains, prestressing and, finally, the formation of a new soil fabric. To meet field conditions, such a type of correlation should be critically reviewed, including the results of calibration chamber tests where the soil mass was densified with a vibrator.
The authors used the classification of Robertson et al. (1986) to present the evolution of soil behaviour type due to the compaction process. In the contributors' opinion, use of the diagram presented by Robertson (1990) or its updated version (Robertson, 2009) would be more appropriate as it allows one to distinguish between normally consolidated and overconsolidated soils. After vibratory compaction in Gdynia, the soil is classified as normally consolidated according to the chart of Robertson (1990) (Figure 33), which is consistent with a mechanism of vibroflotation where only lateral stress increases. After dynamic compaction in Gdańsk, however, the soil is classified as overconsolidated (Figure 34). Such soil type behaviour reflects, in the contributors' opinion, the mechanism of dynamic compaction, where the soil is subjected to dynamic contact vertical stress induced by the pounder impact, as estimated by Jessberger and Beine (1981) and Mayne and Jones (1983).

\section{Authors' reply}

\section{Introduction}

In the paper under discussion (Massarsch et al., 2020) five case histories were investigated, which all showed that the sleeve resistance, $f_{\mathrm{s}}(\mathrm{CPT})$, and horizontal stress index, $K_{\mathrm{D}}$ (DMT), increased independently of the compaction method. The paper demonstrates that permanent changes in horizontal stress do occur as a result of deep vibratory compaction. An important aspect of the proposed approach is that, when assessing preloading, data interpretation should be based on changes of soil parameters rather than on single values after the completed compaction effort. The critique offered by the contributors can be summarised in the following three points.

(a) Changes in sleeve resistance (CPT) or horizontal stress index (DMT) do not reflect changes in horizontal effective stress.

(b) The strong variation of the OCR shows that the authors' proposed horizontal stress concept is incorrect.

(c) An increase in horizontal effective stress cannot be related to a preloading ('overconsolidation') effect. 


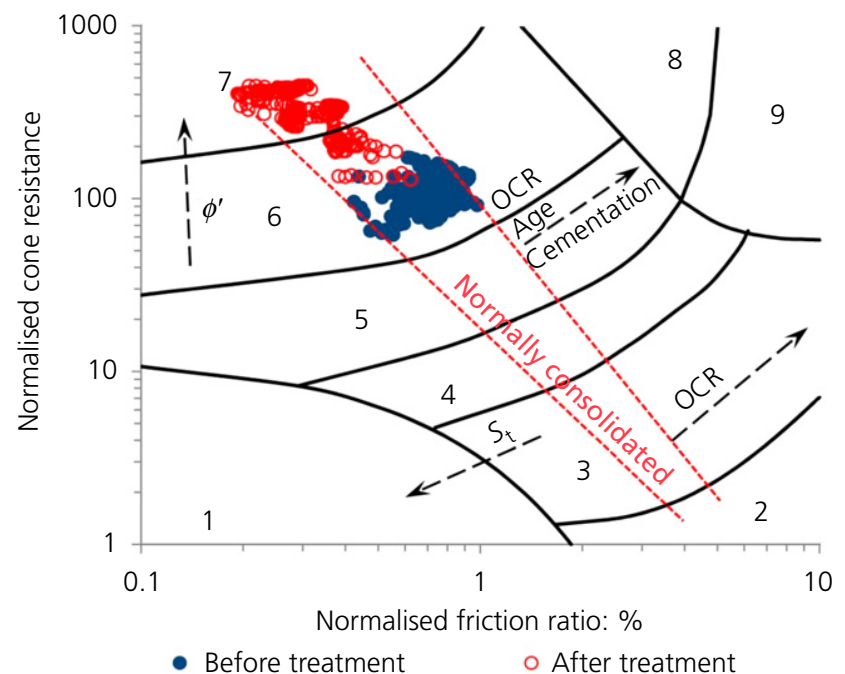

Figure 33. Robertson 1990 chart for soil treated by vibrofloation, Gdynia, Poland (Bałachowski and Kurek, 2015). $\phi^{\prime}$, angle of internal friction; $S_{\mathrm{t}}$, sensitivity

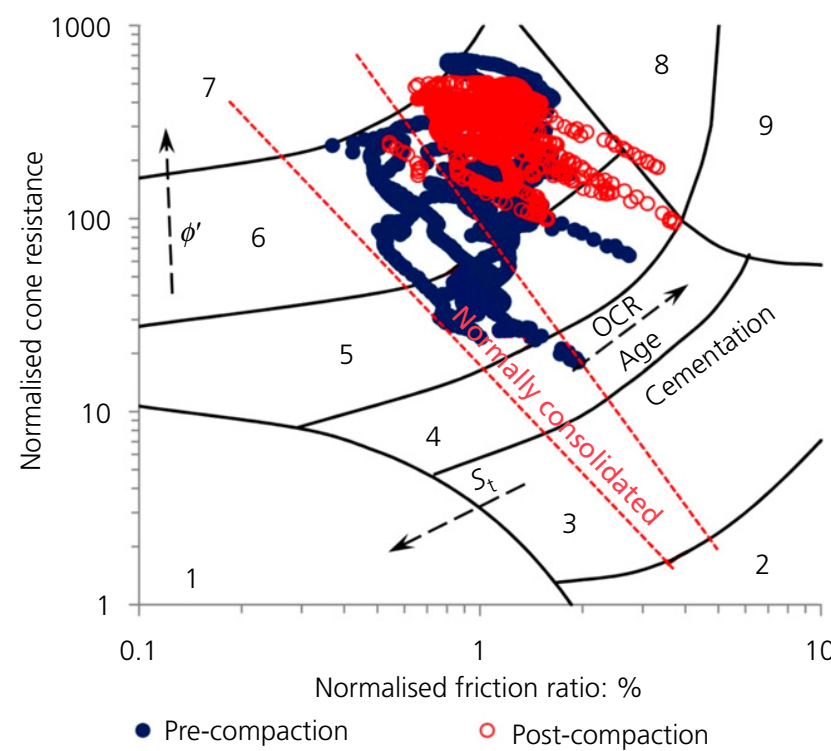

Figure 34. Robertson 1990 chart for soil treated by dynamic compaction, Gdańsk, Poland (Kurek and Bałachowski, 2015)

In the authors' opinion, these three points are based on conjecture rather than factual evidence and do not address the fundamental and widely accepted concepts presented in the paper. Rather, they focus on the fact that the interpretation of field data, in some cases, produces a large scatter.

\section{Questionable quality of geotechnical data}

Two of the contributors were co-authors of two of the case histories (Gdańsk and Gdynia) cited in the original paper. The case history presented by Kurek and Bałachowski (2015)
(CPTU/DMT control of heavy tamping compaction of sands) describes the application of dynamic compaction (heavy tamping) to treat loose to medium dense sand layers and states that 'the cone penetration test CPTU and the dilatometer test DMT were used as main tools of compaction control' (Kurek and Bałachowski, 2015, 2015: p. 2). The case history presented by Bałachowski and Kurek (2015) (Vibroflotation control of sandy soils using DMT and CPTU) describes the application of vibroflotation. However, although the titles of both case histories mention CPTU, the papers omit pore water pressure measurements. Also, the depths to groundwater tables are missing. While CPTU and DMT investigations were carried out at three locations prior to compaction and after compaction, respectively, only the results of one CPT and one DMT before and after treatment are reported. The absence of these measurements may be the cause of the scatter of the OCR values derived from the Gdańsk and Gdynia case histories.

In addition, in the paper by Bałachowski and Kurek (2015) only reports test data for one CPT without pore pressure measurement and one DMT. Vibroflotation causes strong lateral vibrations and the ensuing increase of horizontal stress is evident from the strong increase in $K_{\mathrm{D}}$ measurements. It would be unreasonable to accept that $f_{\mathrm{s}}$ would decrease while $K_{\mathrm{D}}$ would increase. Therefore, the authors' interpretation is that the $f_{\mathrm{s}}$ data are erroneous and that $f_{\mathrm{s}}$ actually increased, similar to $K_{\mathrm{D}}$.

When interpreting geotechnical data from the case histories, the authors did not comment on the accuracy of the reported data. Despite our concern regarding the quality of the two case histories mentioned, due to the large amount of other data from other cited cases, the authors' general conclusion was that horizontal stresses increased in all the case histories, independent of the compaction method. In the following, the points raised by the contributors will be addressed in the order made. The text from the discussion is quoted, followed by the authors' response.

\section{Response to specific comments}

- The approach of Massarsch et al. (2020) to determine the OCR in compacted soil based on sleeve friction and lateral stress index seems to be questionable.

The generalised statement 'seems to be questionable' is rejected because no factual information is given as a base to the statement. The paper addresses changes in horizontal stress due to vibratory compaction. In the authors' opinion, and substantiated by a large number of case histories, both sleeve resistance $f_{\mathrm{s}}$ and horizontal stress index $K_{\mathrm{D}}$ are sensitive to changes in horizontal stress and changes measured between before and after compaction do reflect the preloading effect.

- In Figures 12 and $24 \ldots$ the irregular shape of the OCR with depth and sharp peaks cannot be physically 
explained. Moreover, the OCR values based on sleeve friction and lateral stress index are inconsistent.

The objective of the paper was not to determine the OCR, but to address horizontal stress increase as measured by CPTs and DMTs. The reason for the variation of OCR in Figures 12 and 24 is due to the fact that, after compaction by vibroflotation, $f_{\mathrm{s}}$ is reported to have decreased significantly while $K_{\mathrm{D}}$ increased by a factor of $10-15$. The authors' conclusion is that the accuracy of both the CPT and DMT measurements of the particular case history (Kurek and Bałachowski, 2015) is questionable, which therefore caused a considerable scatter in the evaluation using the cited records.

- For instance, 14 days after dynamic compaction, the OCR values determined with the lateral stress index (Figure 9) are four to seven times higher than those based on sleeve friction (Figure 7).

Compaction was carried out in granular soil with a low fines content. CPT data (cone resistance $q_{\mathrm{c}}$ and sleeve resistance $f_{\mathrm{s}}$ ) show a marked increase 1 day after compaction and only a small increase during the following period. However, the reported DMT $\left(K_{\mathrm{D}}\right)$ measurements show only a slight increase after 1 day, but a strong increase during the following 13 days.

- Even greater inconsistency in the OCR values determined using ... CPTU ... and ... DMT... was shown for vibroflotation (Figures 12 and 14).

As already stated, the sleeve resistance measurements after compaction in the cited case history are questionable (Bałachowski and Kurek, 2015). The contributors stated that 'granular material supply was used from the surface' but did not provide information regarding the added soil volume (Bałachowski and Kurek, 2015: p. 1). It is unreasonable that the friction ratio $R_{\mathrm{f}}$ would decrease by more than $50 \%$.

- The upper bound of the OCR-based $K_{0}$ should correspond to the passive earth pressure coefficient.

Rather than using the OCR, the authors applied the preloading stress margin (the margin between preloading stress and vertical effective stress). This was because the margin is, in effect, the relatively small difference between two larger numbers, which results in uncertainty of the OCR. Moreover, the reported OCR values also reflect the uncertainty (inaccuracy) of the cited geotechnical information.

- Additionally, the use of sleeve friction is generally considered less reliable than the cone resistance, so the proposed correlation (Equation 2) should be used with caution.

The authors agree that sleeve resistance is more prone to variations than cone resistance. However, in the authors' opinion, changes in $f_{\mathrm{s}}$ reflect changes in horizontal stress better than $q_{\mathrm{c}}$. While the accuracy of the absolute value of $f_{\mathrm{s}}$ can be low, the ratio of sleeve resistance (the ratio of sleeve resistance determined after compaction to that before compaction) is significantly more reliable.

- In the contributors' opinion, it would be better to use the OCR correlations based on combined CPTU and DMT tests, as proposed by Baldi et al. (1986), Monaco et al. (2014) or Marchetti (2015).

The use of a combination of CPT and DMT results is potentially useful for determining the stress history of soil deposits. However, in the case of soil compaction, the authors prefer to use changes in horizontal stress based on $f_{\mathrm{s}}$ and $K_{\mathrm{D}}$ separately. In the case of soil compaction, the conservative approach is to assume that, prior to treatment, the soil deposit was normally consolidated.

- Additionally, Figure 17 seems to be erroneous, as the report of sleeve friction elaborated using the data from Figure 15 is higher than one at larger depths.

Figure 17 is correct. As stated in the paper under discussion
... the sleeve resistance down to $5 \mathrm{~m}$ depth was unrealistically low and was neglected. Therefore, the pre-compaction sleeve resistance was not used to determine the increase in horizontal stress, as it would give unacceptably high improvement values.

- To estimate the OCR of compacted sand the authors used Equation 12 based on calibration chamber tests with the soil mass prepared by pluviation and then mechanically overloaded (Lee et al., 2011). Such a procedure is, however, quite different to the mechanisms of deep soil vibratory compaction with rearrangement of grains, prestressing and, finally, the formation of a new soil fabric.

The sample preparation method was described in detail by Choi et al. (2010). Pluviation is a dynamic deposition process that is particularly intense when trying to achieve a density index (relative density) exceeding about $60 \%$. After pluviation, the sample was subjected to one static preloading cycle. If the sample had been subjected to several loading and unloading cycles, as suggested by the contributors, the preloading effect would have been even more pronounced. Therefore, the authors' cited data (Lee et al., 2011) actually underestimate the effect of the preloading.

During vibratory compaction, a soil deposit is subjected to cyclic loading and unloading with a large number of loading cycles. As stated by Rowe (1954), compaction could be interpreted as the repeated application and removal of a static surcharge. Rowe suggested that virtually all peak soil stresses induced by surcharge loading would be retained after 
surcharge removal. Based on the concept of cyclic loading during vibratory compaction, Duncan and Seed (1986) and Symons and Clayton (1992) developed semi-empirical procedures for estimating horizontal stresses due to vibratory compaction. Rearrangement, in the sense of relative motion between soil particles, occurs in a similar manner for compaction and preloading. These considerations also apply to deep compaction of granular soils, a fact that needs to be recognised, as stated by Massarsch and Fellenius (2002).

- ... use of the diagram presented by Robertson (1990) or its updated version (Robertson, 2009) would be more appropriate as it allows one to distinguish between normally consolidated and overconsolidated soils. After vibratory compaction in Gdynia, the soil is classified as normally consolidated according to the chart of Robertson (1990) (Figure 33), which is consistent with a mechanism of vibroflotation where only lateral stress increases. After dynamic compaction in Gdańsk, however, the soil is classified as overconsolidated (Figure 34).

The reliability of soil behaviour type (SBT) charts depends on the accuracy of sleeve resistance measurements. However, soil compaction significantly changes horizontal stresses and thus sleeve resistance, which is demonstrated by the case histories presented in the paper under discussion. Normalised SBT charts apply absolute values of cone resistance and sleeve resistance, which disguises the effect of the rearrangement of the soil fabric, easily leading to erroneous conclusions (e.g. the soil type would have changed as a result of compaction).

Vibroflotation Gdynia: according to the normalised SBT chart provided by the contributors (Figure 33), the soil category changed, but the soil deposit remained normally consolidated. However, this conclusion is, in the authors' opinion, due to inaccurate sleeve resistance measurements. This effect is illustrated in Figure 35, where the same data are plotted in a nonnormalised diagram, as suggested by Massarsch and Fellenius (2002).

The authors agree with the contributors that horizontal stresses increase as a result of vibroflotation. Therefore, it is difficult to follow their assertion, that $f_{\mathrm{s}}-$ which is sensitive to horizontal stress changes (as is $K_{\mathrm{D}}$ ) - would decrease by more than $50 \%$. From Figure 35, it would appear that $f_{\mathrm{s}}$ would decrease in the denser soil layers. This conjecture is contrary to extensive experience published in the literature. For instance, Howie et al. (2000) analysed the effect of vibro-replacement in a sandy soil, similar to the method described by the contributors. Different types of in situ tests were used to evaluate the compaction effect. Testing comprised seismic CPTs, full displacement pressuremeter tests and resistivity CPTs. The CPT data showed that, after treatment, both the cone resistance and the sleeve resistance increased markedly. Howie et al. (2000) concluded

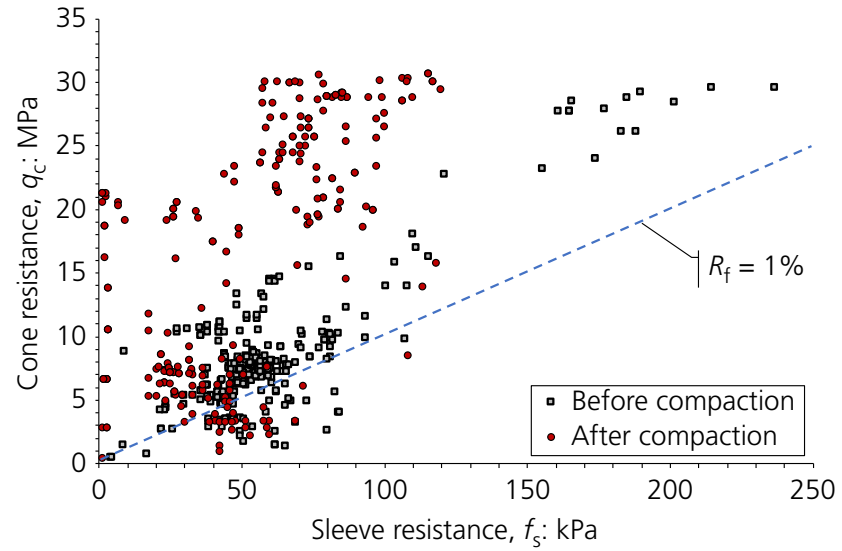

Figure 35. Linear chart of cone resistance against sleeve resistance. Evaluation of soil treated by vibroflotation, Gdynia Poland (Bałachowski and Kurek, 2015). For ease of evaluation, the friction ratio $R_{\mathrm{f}}=1 \%$ is indicated
After ground treatment, changes were observed in tip resistance, pore pressure response, shear wave velocity, the characteristics of pressuremeter curves and bulk resistivity. Some of these changes can be caused by changes in lateral stress as well as by density increases.

Dynamic compaction, Gdańsk: the results from the Gdańsk case history where dynamic compaction was used are replotted in a linear chart of cone resistance against sleeve resistance in Figure 36. Figure 36 clearly shows the effect of the soil treatment. The soil type (friction ratio) remained approximately unchanged. However, $q_{\mathrm{c}}$ and $f_{\mathrm{s}}$ increased by approximately by the same degree. It is obvious from the concepts outlined in the original paper that the treated soil deposit had become preloaded.

The contributors are referred to publications that discuss the limitation of using SBT charts in connection with vibratory compaction (e.g. Asalemi, 2006; Howie et al., 2000; Nguyen et al., 2014). Nguyen et al. (2014: p. 1120) studied the effect of vibratory compaction (vibroflotation with the addition of granular material from the ground surface) on the interpretation of SBT charts, when used for liquefaction evaluation. They showed that, after treatment, the in situ horizontal effective stresses were significantly increased. They concluded the following.

The NCEER 1997 CPT-based liquefaction analysis uses the CPT Soil Behavior Type Index, $I_{\mathrm{C}}$, to infer grain characteristics, such as fines content and plasticity of fines. However, after vibratory ground improvement, the in situ horizontal effective stresses are typically increased (i.e. higher $K_{0}$ ) and are no longer linked to vertical effective stress in the same manner as the case histories. This change in $K_{0}$ has an influence on the CPT results and can result in a reduction of the measured $I_{\mathrm{C}}$ value, and a corresponding 


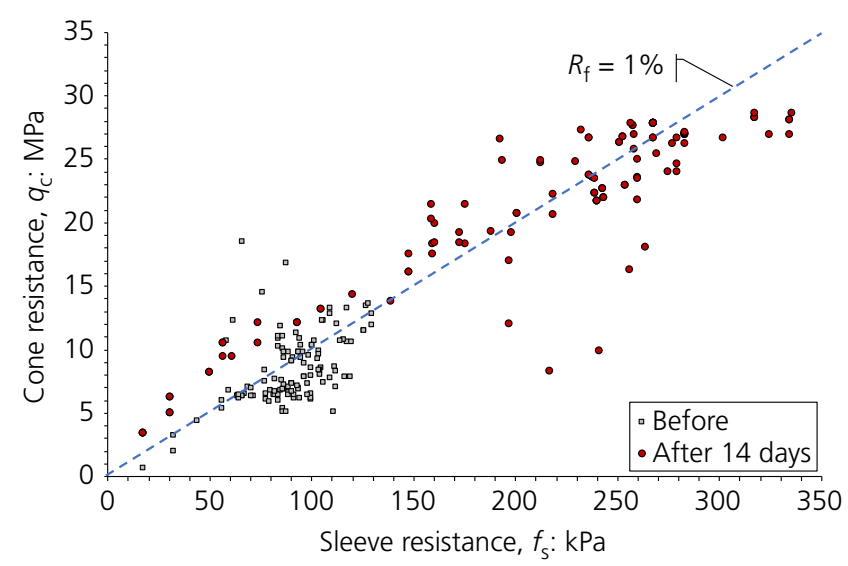

Figure 36. Linear chart of cone resistance against sleeve resistance. Evaluation of soil treated by dynamic compaction, Gdańsk, Poland (Kurek and Bałachowski, 2015). For ease of evaluation the friction ratio $R_{\mathrm{f}}=1 \%$ is indicated

decrease of apparent fines content. However, it is impossible for the vibratory compaction process to produce a decrease in fines content. The authors have performed extensive CPT, SPT, and soil sampling during recent vibro-replacement (stone column) projects in southern California. The $I_{\mathrm{C}}$ values and fine contents of the soil were compared before and after ground improvement. The authors propose a correction method in order to compensate for the shift in $I_{\mathrm{C}}$ and to maintain the same fines content in the pre- and the posttreatment CPT based liquefaction analyses.

- Such soil type behaviour reflects, in the contributors' opinion, the mechanism of dynamic compaction, where the soil is subjected to dynamic contact vertical stress induced by the pounder impact, as estimated by Jessberger and Beine (1981) and Mayne and Jones (1983).

The statement is based on conjecture rather than scientific evidence. As demonstrated in the original paper, showing stress changes as a result of different soil compaction methods, all types of vibratory compaction cause a permanent increase in horizontal stress. For a more detailed description of the vibratory compaction process and thereby induced stress changes, reference is made to, for instance, Duncan and Seed (1986), who state

The compaction of soil represents a process of load application and removal which can result in significant increases in residual lateral earth pressure. Several theories and analytical methods have been proposed to explain and/or analyse the residual lateral earth pressures induced by soil compaction. Common to all of these is the idea that compaction represents a form of overconsolidation wherein stresses resulting from a temporary or transient loading condition are retained to some extent following removal of this peak load.

\section{REFERENCES}

Asalemi AA (2006) Application of Seismic Cone for Characterization of Ground Improved by Vibro-Replacement. Doctoral thesis, University of British Columbia, Vancouver, BC, Canada.

Bałachowski L and Kurek N (2015) Vibroflotation control of sandy soils using DMT and CPTU. In Proceedings of the 3rd International Conference on the Flat Dilatometer (DMT 15), Rome, Italy (Marchetti S (ed.)). International Society for Soil Mechanics and Geotechnical Engineering, London, UK.

Baldi G, Bellotti R, Ghionna V et al. (1986) Flat dilatometer tests in calibration chambers. In Proceedings of In Situ '86 ASCE Specialty Conference on Use of In Situ Tests in Geotechnical Engineering (Clemence SP (ed.)). ASCE, Reston, VA, USA. Special Publication 6, pp. 431-446.

Choi SK, Lee MJ, Choo HW, Tumay MT and Lee WJ (2010) Preparation of a large size granular specimen using a rainer system with a porous plate. Geotechnical Testing Journal 33(1): 1-10.

Duncan JM and Seed RB (1986) Compaction-induced earth pressures under $K_{0}$-conditions. Journal of Geotechnical Engineering ASCE 112(1): $1-22$.

Howie JA, Daniel JA, Asalemi AA and Campanella RG (2000) Combinations of in situ tests for control of ground modification in silts and sands. In Geo-Denver 2000, Denver, CO, USA. American Society of Civil Engineers, Reston, VA, USA.

Jessberger HL and Beine RA (1981) Heavy tamping: theoretical and practical aspects. Proceedings of the 16th International conference on Soil Mechanics and Geotechnical Engineering. IOS Press, Amsterdam, the Netherlands, vol. 3, pp. 695-699.

Kurek N and Bałachowski L (2015) CPTU/DMT control of heavy tamping compaction of sands. In Proceedings of the $3 \mathrm{rd}$ International Conference on the Flat Dilatometer (DMT 15), Rome, Italy (Marchetti S (ed.)). International Society for Soil Mechanics and Geotechnical Engineering, London, UK.

Lee M, Choi S, Kim M and Lee W (2011) Effect of stress history on CPT and DMT results in sand. Engineering Geology 117(3-4): 259-265.

Marchetti S (2015) Some 2015 updates to the TC16 DMT report 2001. In Proceedings of the 3rd International Conference on the Flat Dilatometer (DMT 15), Rome, Italy (Marchetti S (ed.)). International Society for Soil Mechanics and Geotechnical Engineering, London, UK.

Massarsch KR and Fellenius BH (2002) Vibratory compaction of coarse-grained soils. Canadian Geotechnical Journal 39(3): 695-709.

Massarsch KR, Wersäll C and Fellenius BH (2020) Horizontal stress increase induced by deep vibratory compaction. Proceedings of the Institution of Civil Engineers - Geotechnical Engineering 173(3): 228-253, https://doi.org/10.1680/jgeen.19.00040.

Mayne PW and Jones JS (1983) Impact stresses during dynamic compaction. Journal of Geotechnical Engineering ASCE 109(6): 1342-1346.

Monaco P, Amoroso S, Marchetti S et al. (2014) Overconsolidation and stiffness of Venice lagoon sands and silts from SDMT and CPTU. Journal of Geotechnical and Geoenvironmental Engineering ASCE 140(1): 215-227, https://doi.org/10.1061/(ASCE)GT.1943-5606. 0000965.

Nguyen TV, Shao L, Gingery J and Robertson P (2014) Proposed modification to CPT-based liquefaction method for post-vibratory ground improvement. In Proceedings of the ASCE Geo-Congress 2014 Technical Papers: Geo-Characterization and Modeling for Sustainability (Abu-Farsakh M, Yu X and Hoyos LR). ASCE, Reston, VA, USA, pp. 1120-1132.

Robertson PK (1990) Soil classification using the cone penetration test. Canadian Geotechnical Journal 27(1): 151-158, https://doi.org/ 10.1139/t90-014. 
Robertson PK (2009) Interpretation of cone penetration tests - a unified approach. Canadian Geotechnical Journal 46(11): 1337-1355, https://doi.org/10.1139/T09-065.

Robertson PK, Campanella RG, Gillespie D and Greig J (1986) Use of piezometer cone data. In In-Situ'86 Use of In-situ testing in Geotechnical Engineering, GSP 6, ASCE, Reston, VA, USA, Specialty Publication, SM 92, pp. 1263-1280.
Rowe PW (1954) Stress-strain theory for cohesionless soil with applications to earth pressures at rest and moving walls. Géotechnique 4(2): 70-88, https://doi.org/10.1680/ geot.1954.4.2.70

Symons IF and Clayton CRI (1992) Earth pressures on backfilled retaining walls. Ground Engineering 26(3): 26-34. 